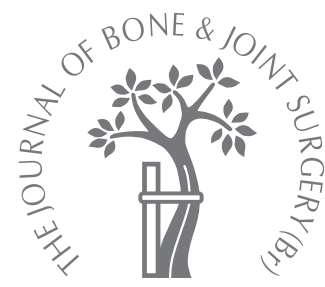

- REVIEW ARTICLE

\title{
New insights into function of the growth plate
}

\author{
CLINICAL OBSERVATIONS, CHONDROCYTE ENLARGEMENT AND \\ A POSSIBLE ROLE FOR MEMBRANE TRANSPORTERS
}

P. G. Bush,

A. C. Hall,

M. F. Macnicol

From the University

of Edinburgh,

Edinburgh, Scotland

\begin{abstract}
The mammalian growth plate is a complex structure which is essential for the elongation of long bones. However, an understanding of how the growth plate functions at the cellular level is lacking. This review, summarises the factors involved in growth-plate regulation, its failure and the consequence of injury. We also describe some of the cellular mechanisms which underpin the increase in volume of the growth-plate chondrocyte which is the major determinant of the rate and extent of bone lengthening. We show how living in situ chondrocytes can be imaged using 2-photon laser scanning microscopy to provide a quantitative analysis of their volume. This approach should give better understanding of the cellular control of bone growth in both healthy and failed growth plates.
\end{abstract}

\section{Regulation of the growth plate}

Skeletal growth is influenced by many factors including parental height, race, gender, health and social group. Karlberg et $\mathrm{al}^{1}$ have described three hormonally-triggered growth curves, namely infantile, childhood and pubertal. This in no way diminishes the importance of fetal growth and birth weight which are thought to influence the development of hypertension, cardiovascular disease and osteoporosis in the adult. ${ }^{2}$ The infantile component, present during the first three years of life, is a sharp, non-linear decelerating curve influenced by nutrition and insulin-like growth factors 1 and 2 . The slowly decelerating childhood component is dependent on growth hormone, is affected by the seasons and is triggered slightly earlier in girls. Illness delays the childhood component by approximately five months, but seems to have no effect on the infantile component.

The pubertal component is sex-steroiddependent. In both girls and boys, oestrogen is the dominant hormone. Low levels stimulate the growth hormone axis causing an early growth spurt in girls and a later pubertal growth spurt in boys. Higher levels of oestrogen subsequently stimulate bone growth directly, causing narrowing and then fusion of the growth plate with cessation of skeletal growth. The effect of hormones on skeletal growth is highly complex. Growth hormone is thought to increase the number of cells in the physeal columns, thyroid hormone potentiates cytoplasmic proliferation and oestrogens which play an important role in triggering closure of the physis after a period of longitudinal growth. ${ }^{3}$

Neuronal factors may also be important since epiphyseal cartilage has its own nerve supply of thin C-fibres, some of which reach the growth plate. Localised sympathectomy was once used to accelerate longitudinal growth in limbs shortened by chronic neurological deficit, albeit with unpredictable success. It is presumed therefore that the nervous system exerts a regulatory function on growth, but the mechanisms by which this is accomplished are unknown. ${ }^{4}$

The nutritional requirements of the physis are exclusively met by the epiphyseal and metaphyseal vasculature. However, the physis is generally avascular, solutes being required to diffuse to the cells through the matrix. Solute fluxes appear to originate from the top, bottom, and a mid-point of the growth plate where cells differentiate from proliferative to hypertrophic phenotypes. ${ }^{5,6}$

Regulation of bone growth by mechanotransduction has also been suggested and is thought to be illustrated by axial correction through adaptation of the growth plate. Typical examples include the spontaneous correction of bow legs in the toddler (Fig. 1) and malunion of a childhood fracture (Fig. 2). Two theories have been proposed to explain this phenomenon. The first maintains that light compression of the physis, as opposed to excessive loading, stimulates growth. Gravity 


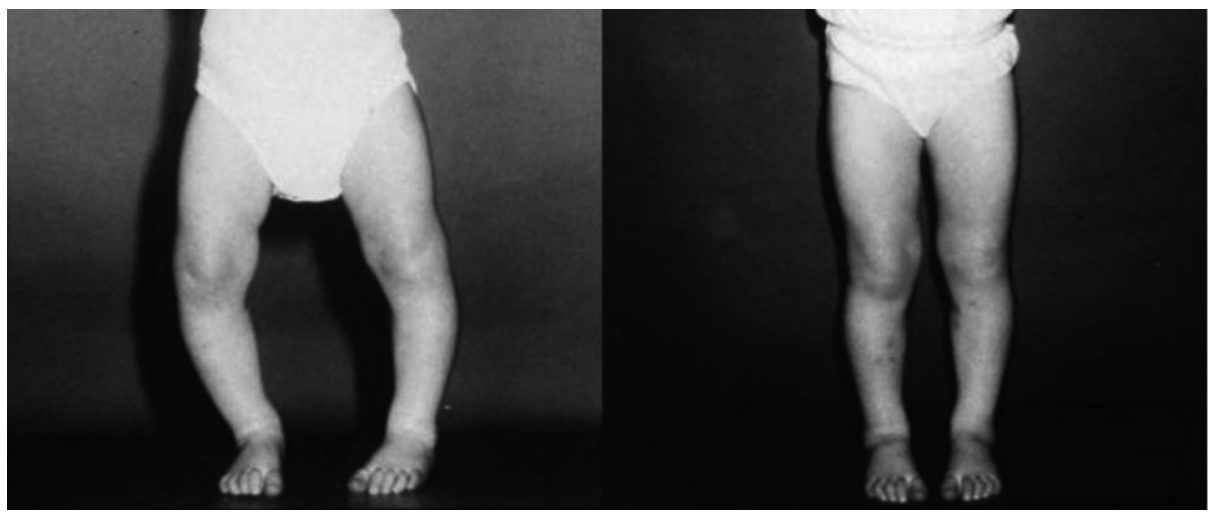

Fig. 1a

Fig. 1b

Photographs showing (a) a toddler, aged 2, with bow-legs who achieved (b) physiological correction with time which is an example of differential activity of the growth plate.

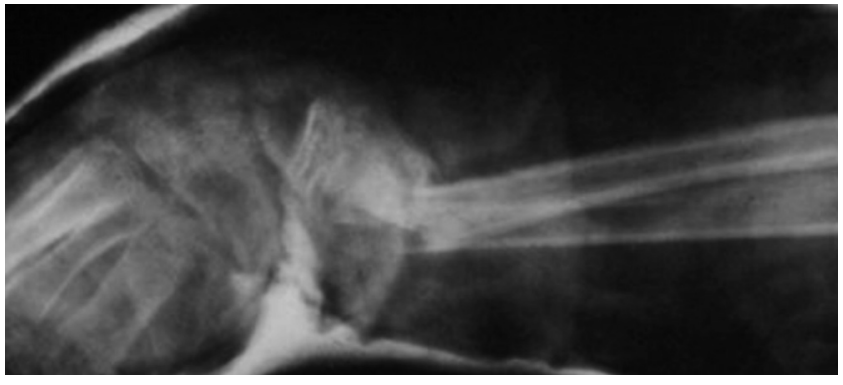

Fig. 2a

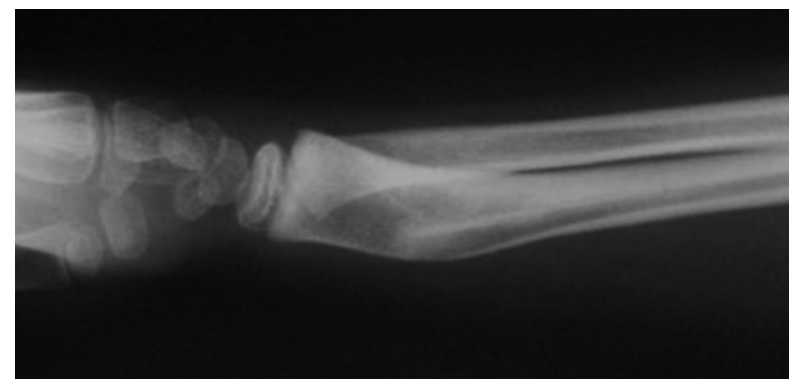

Fig. $2 b$

Radiographs showing a) malunion of an angulated fracture of the distal radius in a 7-year-old boy and b) subsequent re-alignment of the growth plate and bone remodelling.

and physical activity tend to stimulate growth on the concave side of an angular deformity. ${ }^{7,8}$ The second proposes that the growth plate continuously overcomes compressive forces produced by soft-tissue resistance to longitudinal expansion, in addition to muscle tone. Should the cellular columns yield to compression they will shorten on the convex, 'tension' side in angular deformity, and gradually correct the deformity. ${ }^{9}$ Most clinical and experimental observations support the second theory, but the two are not mutually exclusive. For example, Murray et $\mathrm{al}^{10}$ demonstrated that the cellular columns could yield under compression by way of helical tilting, generating a rotational deformity which leads to axial correction. This does not apparently compromise cellular activity.

The structural arrangement of chondrocytes into relatively straight columns supported by a stable subchondral plate is thought to be of crucial importance to normal longitudinal bone growth. However, there have been few studies which have explained the collapse of this delicate structure or why chondrocytes lose the ability to establish a new columnar architecture. Clinical experience and histological studies of Perthes' disease, Blount's disease and slipped capital epiphysis indicate that the resilience of the growth plate can be lost in mid-childhood. The chondrocytes do not appear to lose their capacity for mitotic activity after structural collapse, but are dispersed randomly. ${ }^{11}$

Whatever the regulatory input, the ultimate effect on the activity of the growth plate and structural integrity must be controlled by the component cells and the signals which they receive. Hence, a better understanding of chondrocytes and their mechanisms of growth regulation should help to determine the causes of disease or malfunction of the growth plate.

\section{Injury to the growth plate}

Longitudinal bone growth is clearly dependent upon the normal physiological development of the growth plate and endochondral ossification. However, studies of physeal injury have traditionally been limited to the effects of fracture and other causes have either been briefly addressed or ignored. This reflects the fact that physeal fracture is the most common cause of primary growth arrest and was the first to be documented. ${ }^{12}$ However, other causes are the direct, injurious effects of chemotherapy, certain types of infection (particularly meningococcal septicaemia), neurological disease, burns, juvenile chronic arthritis, uraemia, intoxication (vitamins A, C, D and heavy metals), as well as endocrine disease, malnutrition (malabsorption and protein 


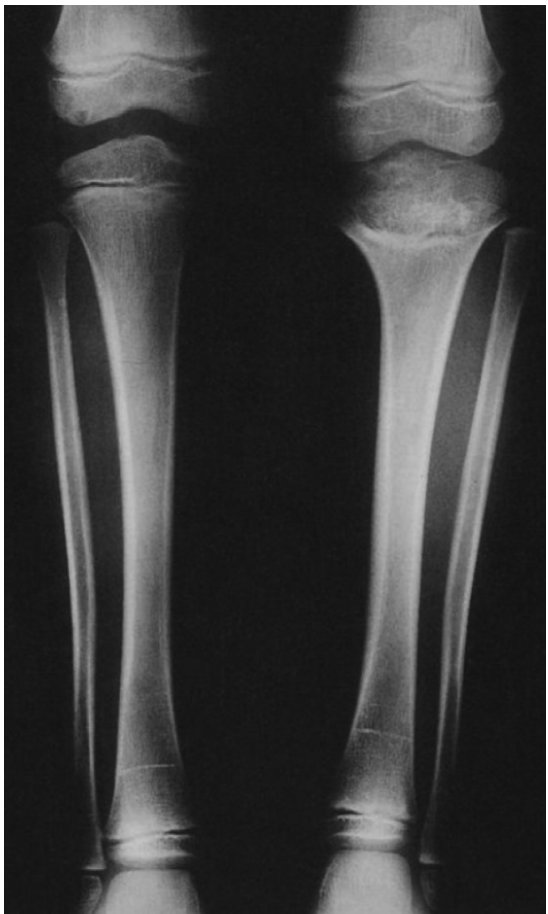

Fig. 3a

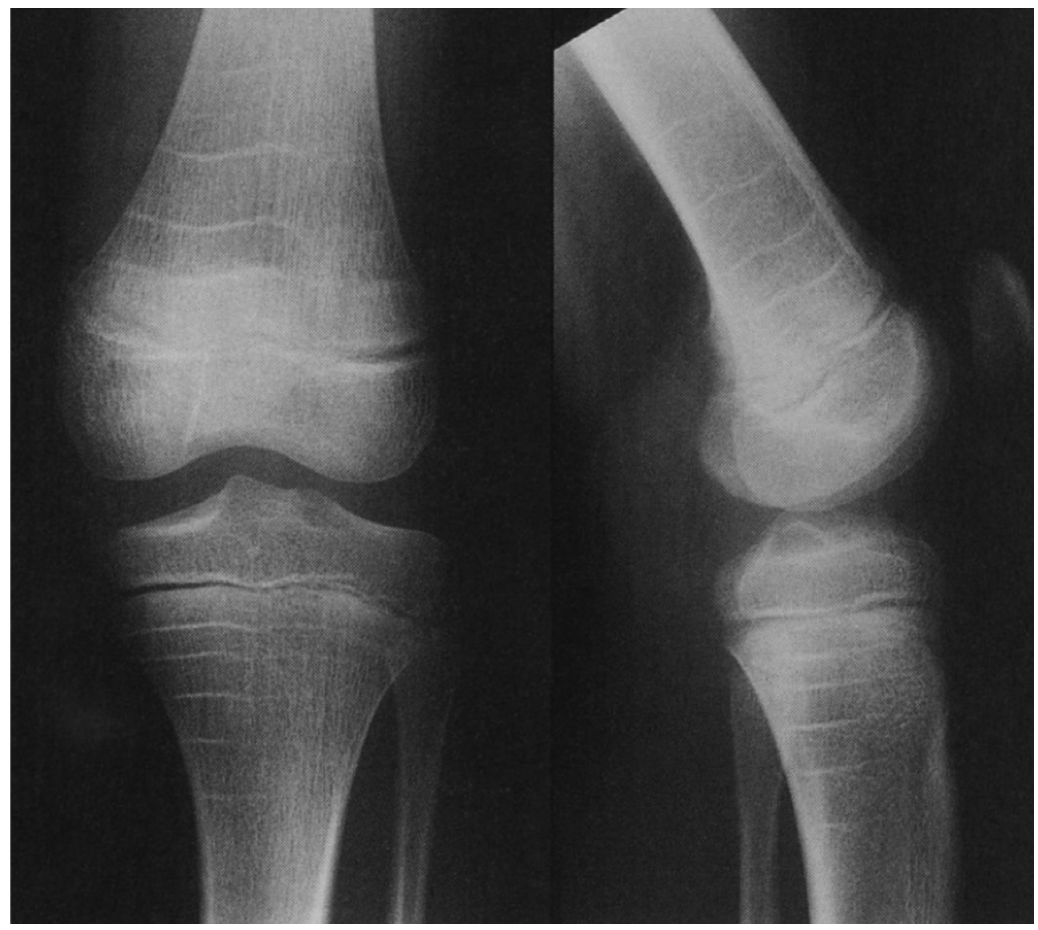

Fig. 3b

Radiographs of Harris growth arrest lines which are formed at the time of mechanical stress or injury showing a) the complete proximal tibial growth arrest at the site of direct damage and associated lines at sites away from the injury and b) the tibia of a girl who went on a family ski-ing holiday every winter.

depletion) and thalassaemia. ${ }^{13}$ The existence of a physeal stress injury inhibiting growth has been disputed, but is now generally accepted. This tends to occur bilaterally in symmetrical physes, and is most commonly seen in the distal radial growth plates of young gymnasts. ${ }^{14}$ There are morphological similarities between the affected physes in this condition and their appearance in some neurological disorders, such as myelomeningocoele and congenital insensitivity to pain. The growth arrest lines as described by Harris ${ }^{15}$ are seen in a variety of conditions (Fig. 3) and are secondary to self-limiting injury of the growth plate.

In 1898, Poland ${ }^{16}$ identified the relationship between the course of a fracture line and the risk of interference with subsequent growth, from which a classification of physeal fractures was derived. Unfortunately, he was unable to produce a comprehensive epidemiological study because of a lack of radiographs. In 1963, Salter and Harris ${ }^{17}$ proposed a classification of fractures of the growth plate from experimental studies on animals. They articulated the principle that a physeal fracture, which did not disrupt the continuity of the germinal layer would not result in growth arrest. This was also true of a fracture which split the growth plate, provided that the physis accurately reduced. Growth arrest after a physeal fracture was presumed to be due to a transphyseal osseous bar, which formed across the gap in an unreduced fracture. Their classification described fracture lines in which the growth plate and the epiphysis were presumed to be intact (type I and type II) and those which produced segmentation of the plate (type III and type IV).

This simple classification was proposed at much the same time as Langenskiöld ${ }^{18}$ identified the 'bone bridge' as a correctable clinical entity. Although Salter and Harris ${ }^{17}$ did not state that growth arrest was invariably avoidable, they recognised that "serious growth disturbance is usually predictable and in certain circumstances can be prevented". They also introduced a fifth, previously unreported type of physeal fracture, indicating that they were well aware of the existence of a type of growth arrest which occurred after trauma and which did not involve segmentation or splitting of the growth plate. This postulated the existence of an injury which suppressed chondrocyte activity in part of the growth plate by means of compression. It was suggested that physeal tissue could be 'crushed to extinction' between epiphyseal and metaphyseal bone on the compression side during angular deformation of a long bone.

The most important point of the Salter-Harris classification was that a fracture of the physis should heal uneventfully if the bone and physeal plate were in continuity. However, there is no guarantee that every fracture will heal, and other lesions such as abrasion of physeal tissue or damage to key vessels may be responsible for this. The final outcome may also be influenced by hormonal, nutritional, biochemical and neurological factors which regulate the function of the growth plate. ${ }^{19}$ However, our understanding of the cell biology of the growth plate, its regulation 


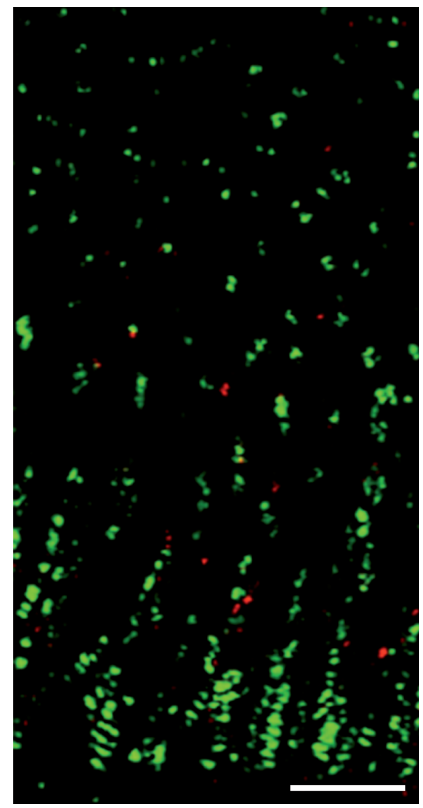

Fig. $4 a$

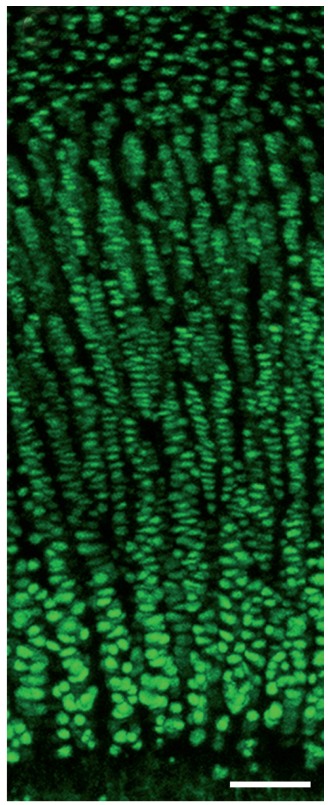

Fig. 4c

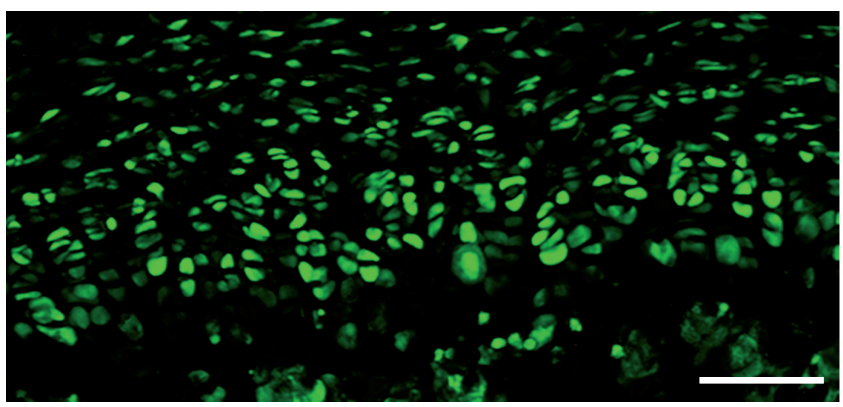

Fig. 4b

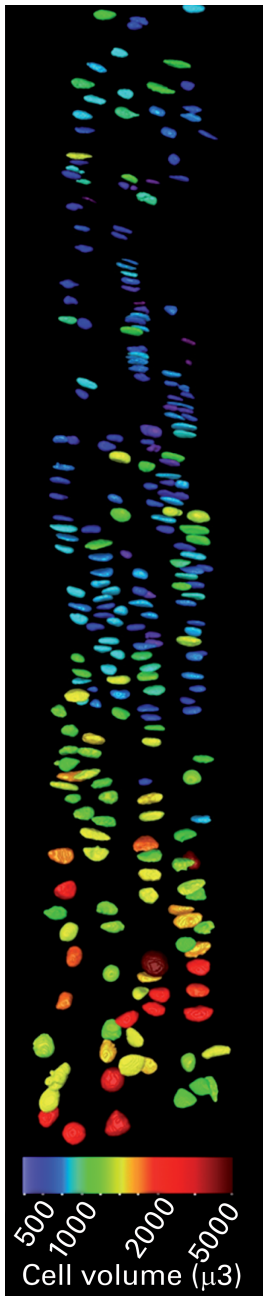

Fig. 4d

Low-power images of living chondrocytes loaded with the vital intracellular fluorescent dye calcein and imaged using confocal and 2-photon laser scanning microscopy showing a) human proximal tibia, ${ }^{37}$ (published with permission from CMAJ 2003;168:459-60), b) human iliac apophysis and c) bovine rib growth plate (scale bar $=100 \mu \mathrm{m} ; \times 10$ objective). Figure $4 \mathrm{~d}-$ High power images of growth plate cell columns from a bovine analysed by computer software (Volocity; Improvision, Coventry, United Kingdom) surface rendered and colour coded according to their volume (see scale) ( $\times 63$ water-dripping objective).

under normal conditions, and how these can be influenced in clinical practice is still at a rudimentary stage. In the remaining sections of this review, we will consider the crucial single cell type responsible, the chondrocyte, and focus in particular on new insights into the mechanism of cell enlargement which is essential for longitudinal bone growth.

\section{Cellular morphology of the mammalian growth plate: a historical perspective}

The growth plate is composed of highly organised and specialised chondrocytes (Fig. 4). Germinal cells, otherwise known as 'reserve', or 'stem' cells are situated next to the epiphysis above clearly organised columns of cells and, after some predetermined signal, begin to divide. This 'multiplication of cells by mitosis' into cells of 'flattened appearance' was elegantly described in the mammalian growth plate by an Edinburgh surgeon, Stump, in $1925^{20}$ in what he originally termed the "serial", but is now commonly called the proliferative zone. Division occurs in a transverse axis and the cells then become orientated longitudinally to form the initial configuration of cell columns. Daughter cells separate by depositing new matrix, a process which continues throughout the growth plate. When cell division ceases, these are described as pre-hypertrophic chondrocytes within the transitional or maturation zone. These pre-hypertrophic cells slowly increase in volume before they progress, as their name suggests, to become rapidly-enlarging hypertrophic chondrocytes and take on a rounded appearance. Stump ${ }^{20}$ described how the nucleus "becomes swollen", and "vacuoles appear in the cytoplasm". 
This description of an 'odematous state', which implied that the increase in volume of the cell was due to swelling, was a prescient observation which will be discussed later.

Hypertrophic zone chondrocytes prepare the surrounding matrix as a "scaffold on which osteoclasts build" ${ }^{20}$ before they sacrifice themselves at the proximal end of the cell columns, in the zone of calcification. This process is often described as 'apoptosis' a phenomenon originally described in other cell types by Kerr, Wyllie and Currie. ${ }^{21}$ A number of features of apoptosis are present, such as condensed nuclear chromatin, but others such as expansion of the rough endoplasmic reticulum and Golgi apparatus depart from the classical description. Thus, although this process appears to be tightly controlled, the term apoptosis may not be strictly accurate, and accordingly an alternative term, 'chondroptosis', has been suggested to describe this specific form of programmed cell death more appropriately. ${ }^{22}$

\section{What determines the rate of chondrocyte enlargement?}

The rate of longitudinal bone growth is controlled by the number of proliferative and hypertrophic zone cells, the rate of division of proliferative chondrocytes, the rate of volume increase of the hypertrophic zone cells and the final volume attained by these cells. ${ }^{23,24}$ It is the volume increase in hypertrophic zone chondrocytes which is responsible for most $(\sim 60 \%)$ of longitudinal bone growth. ${ }^{25} \mathrm{~A}$ stereological examination of sections of 35 day-old rat tibial growth plates ${ }^{26}$ described two phases of chondrocytic volume increase, namely, a gradual $\left(\sim 30 \mu \mathrm{m}^{3} \cdot \mathrm{hr}^{-1}\right)$ increase to about $20 \%$ of their final volume followed by a rapid $\left(\sim 800 \mu^{3} . \mathrm{hr}^{-1}\right)$ increase during the last 20 hours before they reached their final volume.

A cell can increase its volume by classical hypertrophy and/or by swelling. Historically, 'hypertrophy' has been used to describe a general increase in the ultrastructural protein in a cell as seen in cardiomyocytes, ${ }^{27}$ for example, when the heart responds to an increased haemodynamic load. However, for terminally differentiated chondrocytes the appearance of the cells in fixed tissue is more suggestive of 'swelling', which describes the accumulation of fluid. Put simply, the difference between hypertrophy and swelling is the accumulation of 'dry' cell matter (primarily protein) and water, respectively. It can also be described in terms of osmotic fractions with the protein 'dry' cell matter simply 'bulking up' the cells and increasing their size with nonosmotically active constituents. However, for the osmotically-active component, accumulation of fluid occurs by osmosis with freely-mobile water following the movement of osmolytes.

The evidence for fluid accumulation was first intimated by Stump ${ }^{20}$ who described an 'oedematous phase' of cell enlargement. The first electron-microscopic study of the growth plate described a hypertrophic cell as having a "great increase in the volume of cytoplasm matrix and a corresponding decrease in its density". ${ }^{28}$ The first truly quantitative examination of the cytoplasm of chondrocytes was carried out using stereological techniques on fixed tissue and suggested that the hypertrophic zone cells were metabolically active, but that the cytoplasm contained 'holes' which were "probably indicative of chondrocyte swelling in the bottom portion of hypertrophic cells". ${ }^{29}$ Later, a comprehensive study by Buckwalter et $\mathrm{al}^{30}$ also using morphological analysis of electron micrographs, determined the total cell, organelle and matrix volumes along the entire growth plate. They concluded that while synthesis of organelles contributed approximately $20 \%$ to cell enlargement, the principal mechanism was cytoplasmic and nuclear swelling.

Swelling is dependent on the net movement of water into the cell across a water-permeable plasma membrane, and is governed solely by osmotic gradients. For a cell to swell, an osmotic gradient has to be created either by reducing the osmolarity of the solution surrounding the cell and/or by increasing the osmolarity inside the cell. Experiments on human articular chondrocytes in situ, have shown that a major reduction of extracellular osmolarity from the normal level $(\sim 420 \mathrm{mOsm})$ to that of plasma ( 280 mOsm) accounts for an increase in cell volume of only $\sim 30 \% .^{31}$ However, the volume of proliferative zone cells can increase by more than tenfold as they mature into hypertrophic zone chondrocytes; $; 2$ which would require an impossible reduction in extracellular osmolarity. If swelling is the mechanism by which growth-plate chondrocytes hypertrophy, the intracellular osmolarity must increase. There are such mechanisms in most animal cells and they either bring about the net movement of osmolytes across the plasma membrane and/or synthesise intracellular osmolytes which remain trapped within the cell thereby exerting an intracellular osmotic pressure. Both mechanisms lead to swelling of the cell. There has been extensive research into the membrane transport and intracellular metabolic pathways which can bring about this increase in cell volume, a process which has been termed regulatory volume increase. ${ }^{33}$

A histological study by Farnum et $\mathrm{al}^{34}$ attempted to quantify the incorporation of organic osmolytes as the chondrocytes progressed from the proliferative to the hypertrophic zone. They showed that while concentrations of some organic osmolytes did increase, they accounted for only $6 \%$ to $7 \%$ of the swelling required for the increase in cell volume of the hypertrophic zone cells. Again, as with the stereological analysis, these studies were limited to the investigation of fixed tissue sections.

\section{The study of living growth plate chondrocytes in situ} The visualisation of living cells within their extracellular matrix has been revolutionised by advances in confocal laser scanning microscopy and more recently in our laboratory, by 2-photon laser scanning microscopy ${ }^{35}$ which has the advantages of improved cell viability and an increased imaging depth. It has recently been used to determine the rate and routes of solutes diffusion into the intact growth 


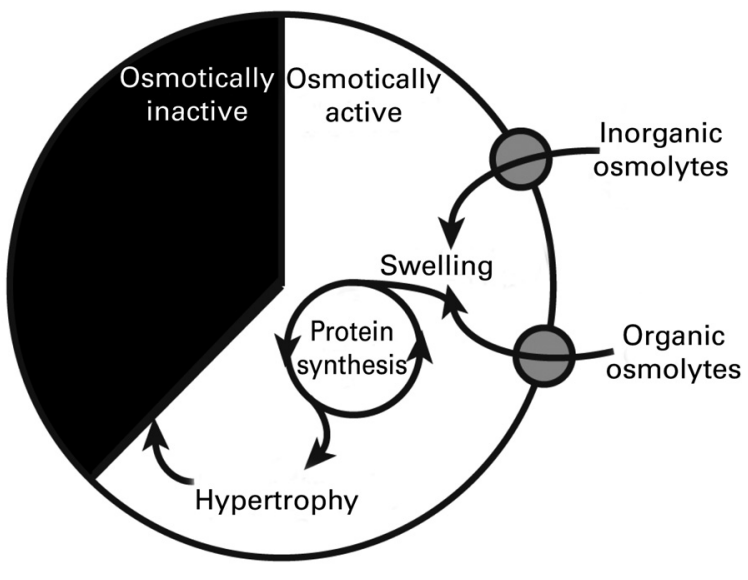

Fig. 5

Diagram of a model to describe chondrocyte enlargement in the growth plate, encompassing both classical hypertrophy and swelling. If a cell is considered to be composed of osmotically-inactive (black) and osmotically-active (white) fractions, for 'dry' cell matter (i.e. proteins) and fluid respectively, then the proportion of chondrocyte enlargement due to hypertrophy and swelling can be represented. The intracellular accumulation of both organic (e.g. amino acids and simple sugars) and inorganic (e.g. $\mathrm{K}^{+}, \mathrm{Na}^{+}$, and $\mathrm{Cl}^{-}$) osmolytes through membrane-transport proteins will create an osmotic gradient which water is obliged to follow thereby driving cell swelling. Accumulated amino acids can then be used in the synthesis of protein, contributing to the total 'dry' cell matter, and increasing cell volume by hypertrophy.

plate in vivo. ${ }^{5,6}$ Both techniques register either endogenous fluorescence (autofluorescence) or exogenous fluorescent molecules (fluorophores), but have the advantage over standard fluorescent microscopy of being able to provide clear optical sections, free from fluorescence 'blur'. Serial optical sections can be acquired and assembled to form a threedimensional (3D) model using specialised computer software. The $3 \mathrm{D}$ data derived from these images are akin to those of modern medical imaging procedures, but are at the cellular or subcellular level. By using an intracellular fluorophore (calcein) to label the cytoplasmic space of the cell, and with the ability to measure cell volume by confocal/2-photon laser scanning microscopy we can investigate the mechanism(s) of the increase in cell volume ${ }^{36}$ in living growth-plate chondrocytes. These techniques reveal a more prominent role for classical 'hypertrophy' in cell enlargement. ${ }^{32}$

Figure 4 shows low-power projected images (overlaid serial optical sections) of a human proximal tibial epiphysis $^{37}$ (Fig. 4a) and iliac apophysis (Fig. 4b). It should be noted that the arrangement of chondrocytes, that is the resting, proliferative, lower and upper hypertrophic, and zone of calcification, are often not the clear classical columnar cell groupings which are seen in animal growth plates (Fig. 4c). It is possible that this reflects the slower rate of growth of human tissues. When magnification of higher power is used, detailed volume data can be determined from the images, ${ }^{36,38}$ as shown in Figure $4 d$, in which bovine rib growth-plate cell images have been colour-coded according to cell volume. The volume of the chondrocyte and linear measurements of length, width and height can be determined relative to their position in the growth plate. ${ }^{32}$ The increase in volume of the hypertrophic zone cells is initially small, but large increases in cell volume become apparent at the base of the cell columns, with, as has previously been reported, ${ }^{32,39}$ a preferential increase in cell length along the direction of bone growth.

The osmotic sensitivity of cells can be determined by performing measurements of cell volume with media of varying osmolarity. Thus living cells can be used to test the hypothesis, derived from fixed specimens, that the increase of volume of growth-plate chondrocytes is driven primarily by swelling and not hypertrophy. A hypotonic challenge can be delivered by changing the osmolarity of the experimental solution, which causes the cells to swell. Conversely, a hypertonic challenge results in cell shrinkage. The size of these volume changes is determined by the osmoticallyinactive and -active fractions, a measure of the 'dry' cell matter and 'fluid content', respectively. Since the changes in cell volume are linearly related to the reciprocal of the extracellular osmolarity, the Boyle van't Hoff relationship, thus, the proportion of the cell water content can be calculated. ${ }^{32}$ Using this methodology we have been able to show that the relative fluid content of cells from the proliferative zone is not different from that of cells undergoing hypertrophy. This suggests that swelling is the mechanism for the increase in cell volume and may have been over-estimated in previous morphological studies on fixed tissue at least until the last stages of hypertrophy. Unfortunately, in our work, the largest of the hypertrophic zone cells were unable to withstand analysis of osmotic challenge, possibly because of fragility induced by swelling. In summary, these experiments suggest that while swelling may be important in the last stages of differentiation, classical hypertrophy is also an essential process which should not be disregarded.

Interestingly, both mechanisms of increase in cell volume must require an increase in the activity of plasma membrane transporters given that there has to be a net intracellular accumulation of osmolytes for swelling or hypertrophy to occur. Hypertrophy demands an increased movement of amino acids and simple sugars into the cell but before these are synthesised into proteins they must act as osmolytes and exert a transient swelling pressure. Because of this, it is possible that the contribution of free inorganic osmolytes as quantified by Farnum et $\mathrm{al}^{34}$ may have significantly underestimated the extent to which these molecules accumulate. In addition to organic osmolytes, the transport of inorganic ions, principally $\mathrm{Na}^{+}$and indirectly $\mathrm{K}^{+}$, as used by other cell types for regulatory volume increase may also be increased. Figure 5 shows a simple model outlining a possible role for membrane transporters in mediating the increase in volume of the growth-plate chondrocyte.

While it is true that evidence for the involvement of membrane transport proteins in hypertrophy of the growth plate is sparse, a study analysing mRNA showed that a 
number of transporters were more highly expressed in hypertrophic chondrocytes than in those found in the proliferative zone. ${ }^{40}$ Specifically, a sodium-dependent neutral amino-acid transport, a glutamate transporter identified in astrocytes, and a sodium-potassium-chloride co-transporter have all been implicated in a volume increase by regulating volume increase in other cell types. ${ }^{41,42}$ By interactions with other amino-acid transporters, and metabolic reactions such as glutamate to and from glutamine, sodium-dependent neutral amino-acid transport and glutamate transporter can influence the cell content of most amino acids, thereby providing the necessary pool for protein synthesis and hence, classical hypertrophy. ${ }^{43}$

We anticipate that any membrane transport process which determines growth-plate activity is directly regulated by the hormonal factors which are known to affect overall bone lengthening. Therefore, investigation of the regulation of membrane transport in growth-plate chondrocyte hypertrophy may provide the answer as to how the growth plate functions in both healthy and abnormal tissue.

Dr P. G. Bush is supported by the Biotechnology and Biological Sciences Research Council (BB/C513985/1).

No benefits in any form have been received or will be received from a commercial party related directly or indirectly to the subject of this article.

\section{References}

1. Karlberg J, Engström I, Karlberg P, Fryer JG. Analysis of linear growth using a mathematical model. I: from birth to three years. Acta Paediatr Scand 1987;76:478-88.

2. Syddall HE, Aihie Sayer A, Dennison EM, et al. Cohort profile: the Hertfordshire cohort study. Int J Epidemiol 2005;34:1234-42.

3. Tanner JM. Growth at adolescence. Second ed. Blackwell Scientific Publications, 1962.

4. Fahey JJ. The effect of lumbar sympathetic ganglionectomy on longitudinal bone growth as determined by the teleoroentgenographic method. J Bone Joint Surg 1936;18:1042-6.

5. Williams RM, Zipfel WR, Tinsley ML, Farnum CE. Solute transport in growth plate cartilage: in vitro and in vivo. Biophys J 2007;93:1039-50.

6. Farnum CE, Lenox M, Zipfel W, Horton W, Williams R. In vivo delivery of fluoresceinated dextrans to the murine growth plate: imaging of three vascular routes by multiphoton microscopy. Anat Rec A Discov Mol Cell Evol Biol 2006;288:91-103.

7. Arkin AM, Katz JF. The effects of pressure on epiphyseal growth: the mechanism of plasticity of growing bone. J Bone Joint Surg [Am] 1956;38-A:1056-76

8. Friberg KS. Remodelling after distal forearm fractures in children. III: correction of residual angulation in fractures of the radius. Acta Orthop Scand 1979;50:741-9.

9. Gelbke $\mathbf{H}$. The influence of pressure and tension on growing bone in experiments with animals. J Bone Joint Surg [Am] 1951;33-A:947-54.

10. Murray DW, Wilson-MacDonald J, Morscher E, Rahn BA, Käslin M. Bone growth and remodelling after fracture. J Bone Joint Surg [Br] 1996;78-B:42-50.

11. Blount WP. Tibia vara, osteochondrosis deformans tibiae. J Bone Joint Surg 1937;19:1-29.

12. Bidder A. Experimente uber die kunstiche Hemmung des Langenwachsthums von Rohrenkonchen durch Reizug und Zestorung des Epiphysenknorpels. Naunyn-Schmiedebergs Archiv fur Pharmakologie und Experimentelle Pathologie 1873;1:248-63.

13. Rang M. The growth plate and its disorders. Edinburgh and London: E. \& S. Livingstone Ltd, 1969.

14. Caine D, Roy S, Singer KM, Broekhoff J. Stress changes of the distal radial growth plate: a radiographic survey and review of the literature. Am J Sports Med 1992;20:290-8
15. Harris HA. The growth of the long bones in childhood with special reference to certain bony striations of the metaphysis and to the role of the vitamins. Arch Int Med 1926;38:785-806.

16. Poland J. Traumatic separation of the epiphysis. London: Smith, Elder \& Co., 1898.

17. Salter RB, Harris WR. Injuries involving the epiphyseal plate. J Bone Joint Surg [Am] 1963;45-A:587-622.

18. Langenskiöld A. An operation for partial closure of an epiphyseal plate in children, and its experimental basis. J Bone Joint Surg [Br] 1975;57-B:325-30.

19. Ogden JA. Skeletal growth mechanism injury patterns. J Pediatr Orthop 1982;2:371-7.

20. Stump CW. The histogenesis of bone. J Anat 1925;59:136-54

21. Kerr JF, Wyllie AH, Currie AR. Apoptosis: a basic biological phenomenon with wide-ranging implications in tissue kinetics. Br J Cancer 1972;26:239-57.

22. Roach HI, Aigner T, Kouri JB. Chondroptosis: a variant of apoptotic cell death in chondrocytes? Apoptosis 2004;9:265-77.

23. Thorngren KG, Hansson LI. Cell kinetics and morphology of the growth plate in the normal and hypophysectomized rat. Calcif Tissue Res 1973;13:113-29.

24. Hunziker EB. Mechanism of longitudinal bone growth and its regulation by growth plate chondrocytes. Microsc Res Tech 1994;28:505-19.

25. Wilsman NJ, Farnum CE, Leiferman EM, Fry M, Barreto C. Differential growth by growth plates as a function of multiple parameters of chondrocytic kinetics. $J$ Orthop Res 1996;14:927-36

26. Breur GJ, Turgai J, Vanenkevort BA, Farnum CE, Wilsman NJ. Stereological and serial section analysis of chondrocytic enlargement in the proximal tibial growth plate of the rat. Anat Rec 1994;239:255-68

27. Morgan HE, Gordon EE, Kira Y, et al. Biochemical mechanisms of cardiac hypertrophy. Ann Rev Physiol 1987;49:533-43.

28. Scott BL, Pease DC. Electron microscopy of the epipyseal apparatus. Anat Rec 1956:126:465-95.

29. Brighton CT, Sugioka Y, Hunt RM. Cytoplasmic structures of epiphyseal plate chondrocytes: quantitative evaluation using electon micrographs of rat costochondral junctions with special reference to the fate of hypertrophic cells. J Bone Joint Surg [Am] 1973;55-A:771-84

30. Buckwalter JA, Mower D, Ungar R, Schaeffer J, Ginsberg B. Morphometric analysis of chondrocyte hypertrophy. J Bone Joint Surg [Am] 1986;68-A:243-55.

31. Bush PG, Hall AC. Passive osmotic properties of in situ human articular chondrocytes within non-degenerate and degenerate cartilage. J Cell Physiol 2005;204:309-19.

32. Bush PG, Parisinos CA, Hall AC. The osmotic sensitivity of rat growth plate chondrocytes in situ: clarifying the mechanisms of hypertrophy. I Cell Physiol 2008;214:621-9.

33. Waldegger S, Steuer S, Risler T, et al. Mechanisms and clinical significance of cell volume regulation. Nephrol Dial Transplant 1998;13:867-74.

34. Farnum CE, Lee R, $\mathbf{O}^{\prime}$ Hara $\mathbf{K}$, Urban JP. Volume increase in growth plate chondrocytes during hypertrophy: the contribution of organic osmolytes. Bone 2002;30:574-81.

35. Bush PG, Wokosin DL, Hall AC. Two-versus one photon excitation laser scanning microscopy: critical importance of excitation wavelength. Front Biosci2007;12:2646-57.

36. Bush PG, Hall AC. The osmotic sensitivity of isolated and in situ bovine articular chondrocytes. J Orthop Res 2001;19:768-78.

37. Huntley JS, Bush PG, Hall AC, Macnicol MF. Looking at the living human growth plate. CMAJ 2003;168:459-60

38. Bush PG, Hall AC. Regulatory volume decrease (RVD) by isolated and in situ bovine articular chondrocytes. J Cell Physiol 2001:187:304-14.

39. Buckwalter JA, Mower D, Schafer J, et al. Growth-plate chondrocyte profiles and their orientation. J Bone Joint Surg [Am] 1985;67-A:942-55.

40. Wang $\mathbf{Y}$, Middleton F, Horton JA, et al. Microarray analysis of proliferative and hypertrophic growth plate zones identifies differentiation markers and signal pathways. Bone 2004;35:1273-93

41. Russell JM. Sodium-potassium-chloride cotransport. Physiol Rev 2000;80:211-76.

42. Bussolati O, Uggeri J, Belletti S, Dall'Asta V, Gazzola GC. The stimulation of $\mathrm{Na}$, $\mathrm{K}, \mathrm{C} 1$ cotransport and of system A for neutral amino acid transport is a mechanism for cell volume increase during the cell cycle. Faseb J 1996;10:920-6.

43. Franchi-Gazzola R, Dall'Asta V, Sala R, et al. The role of the neutral amino acid transporter SNAT2 in cell volume regulation. Acta Physiol (Oxf) 2006;187:273-83. 